\title{
PATTERNS OF USE OF DRUGS IN HYPERTENSION IN GERIATRIC PATIENTS IN THE DEPARTMENT OF MEDICINE AT TERTIARY CARE HOSPITAL OF NEPAL
}

\author{
Raut $B^{1^{*}}$, Khadka $A^{2}$
}

\begin{abstract}
Affiliation
1. Department of Pharmacology, Kathmandu Medical College and Teaching Hospital (KMCTH), Duwakot, Bhaktapur, Nepal.

2. Department of Pharmacology, Nepalese Army Institute of Health Sciences (NAIHS), College of Medicine, Sanobharyang, Kathmandu, Nepal.
\end{abstract}

\section{ARTICLE INFO}

Received : 7 September, 2020

Accepted : 20 November, 2020

Published : 22 December, 202

(C) Authors retain copyright and grant the journal right of first publication with the work simultaneously licensed under Creative Commons Attribution License CC - BY 4.0 that allows others to share the work with an acknowledgment of the work's authorship and initial publication in this journal.

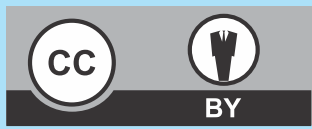

\section{ORA 198}

DOI: https://doi.org/10.3126/bjhs.v5i3.33685

\section{* Corresponding Author}

Dr. Binod Raut

Assistant Professor

Kathmandu Medical College and Teaching Hospital (KMCTH)

Duwakot, Bhaktapur, Nepal

Email ID: binod14raut@gmail.com

ORCID ID: https://orcid.org/0000-0002-1540-6316

\section{Citation}

Raut B, Khadka A. Patterns of Use of Drugs in Hypertension in Geriatric Patients in The Department of Medicine at Tertiary Care Hospital of Nepal. BJHS 2020;5(3)13. 1155-1160.

\begin{abstract}
\section{Introduction}

In Nepal, the prevalence of hypertensive in elderly population is $41.7 \%$ aged 65 years or more. Hypertension increases with age leading to arterial stiffness and endothelial dysfunction. The prevalence of hypertension is $20 \%$ of urban populations. Blood pressure control with the use of antihypertensive drugs reduces cardiovascular complications in geriatric patients.
\end{abstract}

\section{Objectives}

The objective of our study is to know the various patterns of drugs used in geriatrics hypertensive patient along with their co-morbidities and to know the most commonly used antihypertensive drug in geriatric patient.

\section{Methodology}

It was a hospital based cross sectional study involving 130 patients based on non-probability sampling. The study involved the hypertensive elderly patients of age $>65$ years prescribed with antihypertensive drugs. Data were collected from patients attending outpatient department of medicine. Medical and nursing records were analyzed for patient's characteristics (e.g. age, gender), systolic and diastolic BP readings, number of drugs, monotherapy, combination therapy, co morbidities. Data were analysed by using SPSS version 20

\section{Results}

The total 130 geriatric patients under treatment with antihypertensive drugs were included, in which $55.38 \%$ were male and $44.62 \%$ were female. The total numbers of antihypertensive drugs prescribed were 212 either as monotherapy or as a component of a combination therapy. Among these drugs 56.92\% were prescribed as monotherapy, $26.92 \%$ were prescribed as two drugs combination therapy, $12.30 \%$ were prescribed as three drugs combination and $3.84 \%$ were prescribed as four drugs combination therapy. Calcium channel blockers (amlodipine) was the most commonly prescribed antihypertensive.

\section{Conclusion}

The study showed male patient were more predominant hypertensive compare to female. calcium channel blockers group of drugs in which amlodipine was the most commonly prescribed antihypertensive drug and more than half of the patients were in monotherapy.

\section{KEYWORDS}

Amlodipine, anti-hypertensive, geriatrics, losartan 


\section{INTRODUCTION}

Hypertension is a major contributing factor for cardiovascular disease, chronic kidney disease with morbidity and mortality. Worldwide prevalence suggest that by 2030 nearly one quarter death will occur due to complications of hypertension. In Nepal people above 65 years are considered as geriatrics which consists 9.1 percent of the total population, among them the prevalence of hypertensive in elderly population is $41.7 \%$ of which $20 \%$ of them are urban populations. ${ }^{2}$

Many studies suggest that proper antihypertensive therapy in treating hypertension decreases the chances of stroke and other cardiovascular complications in elderly patients. ${ }^{3,4}$ Elderly hypertensive patients also have multiple comorbidities and resistant hypertension requiring multiple drug therapy. ${ }^{4-6}$

As the age progresses the pattern of blood pressure elevation also changes with gradual increase in systolic BP as well as diastolic BP which will lead to progressive increase in arterial stiffness along with anatomical alteration and results in a widening of pulse pressure and ultimately suffers from isolated systolic hypertension (ISH) which is defined as systolic blood pressure (SBP) $>140 \mathrm{~mm}$ of $\mathrm{Hg}$ with diastolic blood pressure (DBP) $<90 \mathrm{~mm}$ of $\mathrm{Hg}$. ISH has poor outcomes with attack of cerebrovascular diseases and coronary artery disease. ${ }^{7,8}$

Elderly patients are prone to develop multiple pathologies which require multiple treatment modalities including multiple drugs or other measures. In such situation, management of hypertension is difficult as there will be altered pharmacokinetics and pharmacodynamics as well as increased risk of adverse drug reactions, toxicities, drug interactions and other unintended hazardous drug related problems. $^{9,10}$

Hypertensive elderly patients require multiple drugs for their treatment. There are no such recommended guidelines to treat hypertension in elderly patient in our Nepalese context. It is the necessity of time to draft the guidelines based on our own evidence and experience to prevent unwanted problems. Hence, this study was planned to study the pattern of use of drugs used in hypertension among geriatrics patients.

\section{METHODOLOGY}

The cross-sectional study involving 130 patients based on non-probability sampling was conducted in the outpatient Department of internal medicine of Tertiary care teaching hospital from February 2019 to July 2019 after obtaining ethical approval from institutional ethical committee. The study involved the elderly patients of age $>65$ years who have been diagnosed with hypertension as per JNC-7 guidelines and prescribed with antihypertensive drugs. The co-morbidities present in elderly patient with hypertension were also recorded but the drugs used for such comorbidities in those patients were excluded from the study. JNC-7 guideline for management of high BP is based on the staging of hypertension; different stages of hypertension are categorized as follows: Pre-hypertension (SBP 120-139 or DBP 80-89 $\mathrm{mmHg}$ ), Stage 1 hypertension (SBP 140-159 or DBP $90-99 \mathrm{mmHg}$ ) and Stage 2 hypertension (SBP $\geq 160$ or $\mathrm{DBP} \geq 100 \mathrm{mmHg}$ ).

Data has been recorded in customized proforma from the patient daily record sheets and reports after taking written consent from patient. Medical and nursing records were analyzed for patient's characteristics (e.g. age, gender, systolic and diastolic BP readings, number of drugs, monotherapy, combination therapy, co morbidities were included. All the collected data were retrieved from proforma and the statistical program for the social sciences (SPSS) package version 20 was used for analysis.

\section{RESULTS}

In this study, 130 geriatric patients under treatment with antihypertensive drugs were included, in which 72 (55.38\%) were male and 58 (44.62\%) were female. The age-wise distribution of patients includes $47.70 \%$ with age range 65 70 years, $26.18 \%$ patients with age range $71-75$ years, $18.46 \%$ of the patients with age range $76-80$ years and $7.69 \%$ with more than 80 years of age shown in figure 1 .

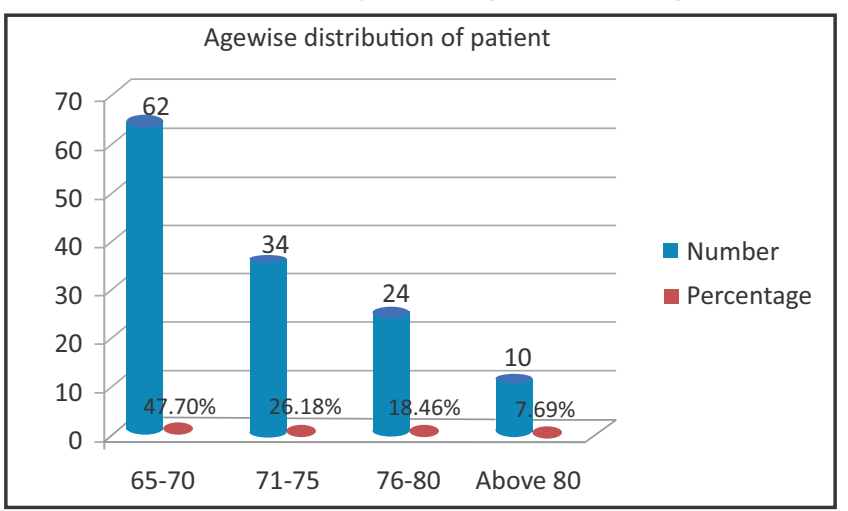

Figure 1: Age-wise distribution of patient

Based on JNC -7 criteria out of total 130 patient, the most patient fall under stage 1 followed by stage 2 (Table 1 ).

Table: 1 Hypertension classification as per the JNC-7
criteria
\begin{tabular}{|l|c|c|}
\hline $\begin{array}{l}\text { Stage of } \\
\text { Hypertension }\end{array}$ & Systolic BP & Diastolic BP \\
\hline Normal & $5(3.84 \%)$ & $18(13.84 \%)$ \\
\hline Pre-hypertensive & $22(16.92 \%)$ & $12(9.22 \%)$ \\
\hline Stage 1 & $57(43.83 \%)$ & $62(47.67 \%)$ \\
\hline Stage 2 & $46(35.37 \%)$ & $38(29.22 \%)$ \\
\hline
\end{tabular}

The total numbers of antihypertensive drugs prescribed were 212 either as monotherapy or as a component of a combination therapy (Table 2). Among them 56.92\% were prescribed as monotherapy, $26.92 \%$ were prescribed as two drugs combination, $12.30 \%$ were prescribed as three drugs combination and $3.84 \%$ were prescribed as four drugs combination therapy. 


\begin{tabular}{|c|c|c|c|}
\hline Modality of Therapy & Drug Groups & Number & Total (130) \\
\hline \multirow{6}{*}{ Monotherapy } & $\mathrm{CCB}$ & 38 & \multirow{6}{*}{$74(56.92 \%)$} \\
\hline & Diuretics & 15 & \\
\hline & ARB's & 8 & \\
\hline & ACEI's & 6 & \\
\hline & BB & 4 & \\
\hline & Others & 3 & \\
\hline \multirow{8}{*}{ Combination of two drug } & $\mathrm{CCB}+$ Diuretics & 11 & \multirow{8}{*}{$35(26.92 \%)$} \\
\hline & $C C B+A R B^{\prime} s$ & 6 & \\
\hline & CCB + ACEI's & 5 & \\
\hline & $\mathrm{CCB}+\mathrm{BB}$ & 3 & \\
\hline & Diuretics +ARB's & 4 & \\
\hline & Diuretics + ACEI's & 3 & \\
\hline & $B B+A R B^{\prime} s$ & 2 & \\
\hline & BB + ACEI's & 1 & \\
\hline \multirow{6}{*}{ Combination of three drug } & CCB + Diuretics + ARB's & 4 & \multirow{6}{*}{$16(12.30 \%)$} \\
\hline & CCB + Diuretics + ACEI's & 4 & \\
\hline & $\mathrm{CCB}+$ Diuretics + BB & 3 & \\
\hline & Diuretics + BB + ARB's & 2 & \\
\hline & Diuretics + BB + ACEI's & 2 & \\
\hline & $C C B+B B+A R B^{\prime} S$ & 1 & \\
\hline Combination four drug & $\mathrm{CCB}+$ Diuretics + ARB's +BB & 3 & $5(3.84 \%)$ \\
\hline
\end{tabular}

$\mathrm{CCB}=$ Calcium channel Blockers, $\mathrm{ARB}$ 's = Angiotensin Receptors Blockers, $\mathrm{ACEI}$ 's = Angiotensin Converting Enzyme Inhibitors, $\mathrm{BB}=$ Beta Blockers

Among the overall prescription, calcium channel blockers were $37.73 \%$ in which common drugs prescribed from this group were (amlodipine and nifedipine), diuretics $25 \%$ in which most common drugs prescribed in this group were (furosemide, hydrochlorothiazide, and spironolactone), angiotensin receptor blockers $14.15 \%$ in which most common prescribed drugs were (losartan, telmisartan, and valsartan), angiotensin converting enzyme inhibitors
$10.84 \%$ in which the most common prescribed drugs were (enalapril, ramipril and lisinopril), beta blockers $10.84 \%$ with most common prescribed drugs were (atenololol, metoprolol), and $1.41 \%$ were alpha blockers (doxazosin) and combination of alpha-beta blockers (carvedilol) were prescribed. The frequency of individual prescribed antihypertensive drugs is shown in table 3.

Table: 2 Classification of patient based on number of use of Drugs

\begin{tabular}{|c|c|c|c|}
\hline Drug Groups & Drugs & Frequency & Percentage of drugs \\
\hline \multirow{2}{*}{ Calcium channel blockers } & Amlodipine & 57 & \multirow[b]{2}{*}{$37.73 \%$} \\
\hline & Nifedipine & 23 & \\
\hline \multirow{3}{*}{ Diuretics } & Furosemide & 25 & \multirow[b]{3}{*}{$25 \%$} \\
\hline & Hydrochlorothiazide & 15 & \\
\hline & Spironolactone & 13 & \\
\hline \multirow{3}{*}{ Angiotensin Receptor blockers } & Losartan & 16 & \multirow[b]{3}{*}{$14.15 \%$} \\
\hline & Telmisartan & 9 & \\
\hline & Valsartan & 5 & \\
\hline \multirow{3}{*}{ Angiotensin converting enzyme blockers } & Enalapril & 12 & \multirow[b]{3}{*}{$10.84 \%$} \\
\hline & Lisinopril & 7 & \\
\hline & Ramipril & 4 & \\
\hline \multirow{2}{*}{ Beta Blockers } & Atenolol & 15 & \multirow[b]{2}{*}{$10.84 \%$} \\
\hline & Metoprolol & 8 & \\
\hline \multirow{2}{*}{ Others } & Carvedilol & 1 & \multirow[b]{2}{*}{$1.41 \%$} \\
\hline & Doxazosin & 2 & \\
\hline Total & \multicolumn{2}{|c|}{212} & \\
\hline
\end{tabular}


Among all hypertensive geriatric patients, the comorbid conditions was found with $26.18 \%$ diabetes mellitus, $11.55 \%$ chronic kidney diseases, $10 \%$ dyslipidemia, $10.78 \%$ cerebro-vascular accident (CVA) and hemiplegia, 9.24\% hyperthyroidism, $7.7 \%$ chronic obstructive pulmonary disease, $6.93 \%$ coronary artery disease, $5.39 \%$ others like metabolic disease and benign prostate hyperplasia (Figure 2). ARBs were prescribed more in diabetes with hypertension followed by angiotensin converting enzyme-inhibitors (ACE-I), calcium channel blockers (CCBs) and thiazides. The most common drug prescribed in diabetes with hypertension was losartan (12.2\%) and in CVA with hemiplegia was combination of ARBs and Thiazides.

\section{Co-Morbidities with Hypertension}

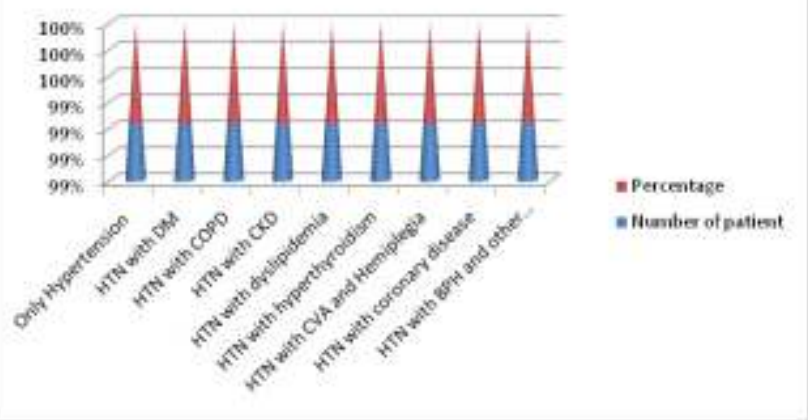

Figure 2: Co-morbidities with Hypertension

\section{DISCUSSION}

In this study hypertension is found to be more prevalent in male patient compare to female patient in which $55.38 \%$ were male whereas $44.62 \%$ were female the reason could be due to habbit of consuming alcohol, smoking, over weight and obesity which was more in male patient which may have lead to increase in blood pressure Similar study done in Nepal also found that the prevalence of hypertensive above 65 years of age is increasing day by day in which the male patient are more prone compared to female patients. ${ }^{11}$ This gender difference in case of developing hypertension has been well documented in previous researches conducted in Nepal. ${ }^{12-14}$

On the basis of age-wise distribution, maximum (47.70\%) were from the age $65-70$ years followed by $26.18 \%$ of $71-75$ years and $7 \%$ were from above 80 years of age. Similar study conducted in Nepal had also found the $72 \%$ of the patients were from age group 65- 70 years in which male were $69 \%$ and $31 \%$ were female which resembles with our study. ${ }^{15}$

On the basis of drug prescription $56.92 \%$ of the patients were prescribed with monotherapy drug followed by $26.92 \%$ with two drug combination and $12.30 \%$ with three drug combination and $3.8 \%$ with four drug combination. Calcium channel blockers were the most commonly prescribed antihypertensive followed by diuretics and ARB's as the monotherapy. It resembles with another study in which $48 \%$ of patients were prescribed monotherapy which is quite less compare to our study and $47 \%$ of patients were prescribed with dual combination therapy which was quite more compare to our study. Calcium channel blockers were the most commonly used first line antihypertensive due to its extra added beneficial effects like slowing heart rate, relieve chest pain and control irregular heartbeat. It also prevents calcium from entering the cells of the heart and arteries and also lower blood pressure. Similar study had found $47.7 \%$ patients were prescribed with Calcium channel blockers (CCBs) which was the most frequently prescribe antihypertensive which almost resembles with our study whereas in another group there was contrast in which there was $14.6 \%$ drugs were prescribed in our study in which it was prescribed to $35.5 \%$ of patients with angiotensin receptor blockers (ARBs). ${ }^{16}$

Calcium channel blockers were most frequently prescribed group of drugs in which amlodipine was most commonly prescribed followed by losartan and telmisartan which was also similar with the Datta $S$ et al., and Almas $A$ et al. ${ }^{17-}$ ${ }^{19}$ Similarly calcium channel blockers with diuretics were most commonly combined in combination therapy followed by $C C B+A R B$ 's and diuretics +ARB's. $C C B$ + Diuretics + ARB's were found to be more common combination in three drug combination. $C C B$ + diuretics + $A R B$ 's and $B B$ were combined in four drug therapy. In similar study on antihypertensive drug conducted in Ontario, Canada, between 1999 and 2010 among hypertensive patients aged 66 years or more, have found angiotensin converting enzyme inhibitors, angiotensin receptor blockers and calcium channel blockers with better persistence than beta blockers and diuretics. ${ }^{20}$ In our study, beta blockers were found to be prescribed less which justify the study which is coherent with international guidelines (JNC-7) which mentioned that BBs should not be prescribed in very elderly patients unless in post myocardial infarction or coronary heart failure. ${ }^{21}$

Among the total 130 patient, it was found that 212 drugs were prescribed, in which half of the patient were prescribed with monotherapy whereas in another study, around 4-6 drugs per patient were given which was more than our study, similarly in another study conducted in Malayasia had found that the average number of drugs prescribed was 1.80 per patients which was almost similar to our study. ${ }^{22}$ The average number of drugs prescribed per person was less than two which signifies that at Least two antihypertensive drugs are required to achieve target blood pressure. $^{23}$ The number of drugs required to control blood pressure must be more than two. In our study, doxazosin, alpha receptor blocker, was found to be used due to the comorbid condition-benign prostate hyperplasia.

Among the geriatric patient it was found that $26.18 \%$ were suffered from hypertension along with diabetes mellitus, similarly $11.55 \%$ were suffering from chronic kidney diseases, $10 \%$ of them were suffering from dyslipidemia, $10.78 \%$ were also suffering from cerebro-vascular accident and hemiplegia, 9.24\% were suffering from hyperthyroidism, $7.7 \%$ were suffering from chronic obstructive pulmonary disease, $6.93 \%$ were having coronary artery disease, 5.39\% were suffering from other metabolic disease with benign prostate hyperplasia. Similar study had also found that $52.6 \%$ of patients had dyslipidemia, $29.0 \%$ had diabetes, 
$15.8 \%$ had ischemic heart disease, and $7.9 \%$ had a stroke in which our study almost coincide with finding of hypertension along with diabetes mellitus but has contrast results in respect to dyslipidemia which is quite less in our study which was probably due to different aspect of dietary intake habbit. ${ }^{16}$ Another similar study had also concluded that untreated and uncontrolled high blood pressure was the key factor for developing wide range of complications like pulmonary hypertension, heart failure, ischeamic heart disease, renal disease, cerebrovascular disease like stroke, which has led to early disability and death. ${ }^{24}$ similar study suggest that due to multiple comorbidities with higher cardiovascular risk in old patients aged with 66-79 years under treatment on antihypertensive also indicates that the incidence of cardiovascular events like myocardial infarction, ischemic heart disease, stroke/TIA, congestive heart failure was 2 -fold higher. ${ }^{25}$ So it is utmost required to carefully assess the need for antihypertensive with minimum number of combination of drugs along with long acting drugs covering for missed doses. Elderly patients with hypertension often coexist with various diseases such as coronary heart disease, heart failure, cerebrovascular disease, renal insufficiency, stroke and diabetes mellitus. Blood pressure reduction is one of the most powerful pharmacological methods to reduce the cardiovascular events and mortality. There were certain evidence which signifies that lowering systolic blood pressure and diastolic blood pressure by 20 and $10 \mathrm{mmHG}$ respectively may reduce the incidence of stroke by $40 \%-50 \%$ and to coronary heart disease to 15 to $30 \% .{ }^{26}$ similarly the pharmacological therapy of drugs for reduction in blood pressure for elderly patient above 65 years should be targeted to atleast 130 $\mathrm{mmHG}$ systolic and $80 \mathrm{mmHG}$ diastolic blood pressure in order to prevent cardiovascular complications. ${ }^{27}$

\section{CONCLUSIONS}

Our study shows that the most commonly prescribed drug was from the group calcium channel blockers followed by diuretics and angiotensin receptors blockers. Amlodipine was the most commonly prescribed antihypertensive drug and more than half of the patients were prescribed with monotherapy. Both monotherapy as well as combination therapy are needed in majority of elderly patient to control blood pressure.

\section{REFERENCES}

1. Kjeldsen S, Feldman RD, Lisheng $L$ et al. Updated national and international hypertension guidelines: a review of current recommendations. Drugs 2014; 74: 2033-51.PMID: 25315030 DOI: 10.1007/s40265-014-0306-5

2. Maskey A, Sayami A, R PM. Coronary Artery Disease: An emerging epidemic in Nepal. J Nepal Med Assoc. 2003; 42:122-4. https://doi.org/10.31729/jnma.807

3. Pant S, Neupane P, Ramesh KC, Barako $\Theta$ M. Hypertension in the elderly: Are we all on the same wavelength? World J Cardiol 2011; 3:263-6. DOI: $10.4330 /$ wjc.v3.i8.263

4. Prisant LM, Moser M. Hypertension in the elderly. Can we improve results of therapy? Arch Intern Med 2000; 160:283-9.DOI: 10.1001/archinte.160.3.283

\section{RECOMMENDATIONS}

Hypertension is a common and very important modifiable risk factor for cardiovascular morbidity and mortality. Initiating antihypertensive treatment is recommended when BP exceeds $140 / 90 \mathrm{mmHg}(130 / 85 \mathrm{mmHg}$ in those with diabetes, kidney disease, and cardiovascular disease). Therapeutic lifestyle changes should be encouraged in elderly hypertensive patients and include dietary sodium restriction, increased physical activity, weight loss and maintenance of ideal body weight, and moderation of alcohol consumption. In the elderly, pharmacological treatment of hypertension provides significant reductions in cardiovascular risk. Combination antihypertensive therapy is usually indicated in elderly hypertensive patients, and acceptable regimens include calcium channel blockers, diuretics and renin-angiotensin system blocker.

\section{LIMITATIONS OF THE STUDY}

- Sample size of the study was small should have included more number of elderly hypertensive patients to confirm more relevant outcome.

- Single center study should have included more centers to find out the outcome on various aspects of the patient with rural and urban variations.

- Should have included various adverse effects reported by elderly patients in order to choose effective drug along with avoidance of polypharmacy.

\section{ACKNOWELDGEMENTS}

We are grateful to the department of internal medicine of KMCTH for their help and support. We would like to gratitude Dr Nimesh Poudel for his guidance during data collection in the department of Medicine at KMCTH.

\section{CONFLICT OF INTEREST}

None

\section{FINANCIAL DISCLOSURE}

None
5. Ogihara T, Hiwada K, Morimoto S, Matsuoka H, Matsumoto M, Takishita S, et al. Guidelines for treatment of hypertension in the elderly-2002 revised version. Hypertens Res 2003; 26:1-36.DOI: 10.3143/geriatrics.36.576

6. Chaudhry KN, Chavez P, Gasowski J, Grodzicki T, Messerli FH. Hypertension in the elderly: Some pracӨcalconsideraӨons. Cleve Clin J Med 2012; 79:694-704. DOI: https://doi.org/10.3949/ ccjm.79a.12017

7. Mackenzie IS, MacDonald TM. Hypertension in octogenarians treatment strategies and challenges. EurCardiol 2011; 7: 25-8. https://doi.org/10.15420/ecr.2011.7.1.25

8. National High Blood Pressure Education Program Working Group Report on Hypertension in the Elderly. National High Blood Pressure Education Program Working Group. Hypertension 1994; 23:275-85.PMID: 8125550 
9. Cunningham G, Dodd TR, Grant DJ, Murdo ME, Richards RM. Drugrelated problems in elderly patients admitted to Tayside hospitals, methods for prevention and subsequent reassessment. Age Ageing 1997; 26:375-82.DOI: 10.4103/2229-3485.103595

10. Mannesse CK, Derkx FH, Ridder MA, Man Veld AJ, Van D, Cammen TJ. Adverse drug reactions in elderly patients as contributing factor for hospital admission: Cross sectional study. BMJ 1997; 315:10578. DOI: 10.1136/bmj.315.7115.1057

11. Hasan M, Sutradhar I, Akter T, Das Gupta R, Joshi H, Haider MR, et al. (2018) Prevalence and determinants of hypertension among adult population in Nepal: Data from Nepal Demographic and Health Survey 2016. PLoS ONE 13(5): e0198028. https://doi.org/ 10.1371/journal. pone.0198028

12. Vaidya A, Pathak RP, Pandey MR. Prevalence of hypertension in Nepalese community triples in 25 years: a repeat cross-sectional study in rural Kathmandu. Indian Heart J. 2012; 64(2):128-31. https://doi.org/10.1016/S0019-4832(12)60045-5 PMID: 22572484

13. Aryal KK, Mehata S, Neupane S, Vaidya A, Dhimal M, Dhakal P, et al. The burden and determinants of non communicable diseases risk factors in Nepal: findings from a nationwide STEPS survey. PLoS One. 2015; 10(8):e0134834. https://doi.org/10.1371/journal. pone.0134834 PMID: 26244512

14. Chataut J, Adhikari R, Sinha N. Prevalence and risk factors for hypertension in adults living in central development region of Nepal. Kathmandu Univ Med J (KUMJ). 2012; 9(1):13-8. DOI: 10.3126/kumj.v9i1.6255

15. Mohd AH, Mateti UV, Konuru V, Parmar MY, Kunduru BR. A study on prescribing patterns of antihypertensives in geriatric patients. Perspect Clin Res. 2012;3(4):139-142. doi:10.4103/2229-3485.103595.

16. Lee JH, Kim KL, Cho MC. Current status and therapeutic considerations of hypertension in the elderly. Korean J Intern Med. 2019; 34(4):687-95. https://doi.org/10.3904/kjim.2019.196

17. Datta $\mathrm{S}$. Use of antihypertensives in patients having associated renal parenchymal disorders: Cross sectional prescription pattern study in a tertiary care hospital. Int J Pharm Sci Drug Res 2011; 3:256-9.doi: 10.4103/2229-3485.103595

18. Almas, A., ur Rehman Iqbal, S., Ehtamam, A. et al. Spectrum of antihypertensive therapy in South Asians at a tertiary care hospital in Pakistan. BMC Res Notes 4, 318 (2011). https://doi.org/10.1186/ 1756-0500-4-318
19. Neal B, MacMahon S, Chapman N. Effects of ACE inhibitors, calcium antagonists, and other blood-pressure lowering drugs: Results of prospectively designed overviews of randomised trials. Blood pressure lowering treatment trialists' collaboration. Lancet 2000;356:1955-64.DOI: 10.1016/s0140-6736(00)03307-9

20. Tu K, Anderson LN, Butt DA, Quan H, Hemmelgarn BR, Campbell NR, et al. . Antihypertensive drug prescribing and persistence among new elderly users: implications for persistence improvement interventions. Can J Cardiol. (2014) 30:647-52. 10.1016/j.cjca. 2014.03.017 [PubMed] [CrossRef] [Google Scholar]

21. Zeglin MA, Pacos J, Bisognano JD. Hypertension in the very elderly: Brief review of management. Cardiol J 2009; 16:379-85. PMID: 19653187.

22. Lim KK, Sivasampu S, Khoo EM. Antihypertensive drugs for elderly patients: a cross- sectional study. Singapore Med J. 2015; 56(5):291-297. doi:10.11622/smedj.2015019

23. Giles T. Rationale for combination therapy as initial treatment for hypertension. J ClinHypertens (Greenwich) 2003; 5(4 Suppl 3):4-11. [PubMed] [Google Scholar]

24. Lionakis N, Mendrinos D, Sanidas E, Favatas G, Georgopoulou M. Hypertension in the elderly. World J Cardiol. 2012; 4(5):135. https://doi.org/10.4330/wjc.v4.i5.135 PMID: 22655162.

25. Yang Q, Chang A, Ritchey MD, Loustalot F. Antihypertensive medication adherence and risk of cardiovascular disease among older adults: a population-based cohort study. J Am Heart Assoc. (2017) 6:e006056. 10.1161/JAHA.117.006056 [PMC free article] [PubMed] [CrossRef] [Google Scholar]

26. Daskalopoulou SS, Khan NA, Quinn RR, et al. The 2012 Canadian hypertension education program recommendations for the management of hypertension: blood pressure measurement, diagnosis, assessment of risk, and therapy. Can J Cardiol. 2012; 28 : 270-287.doi: 10.1016/j.cjca.2011.03.015

27. Alsarah A, Alsara O, Bachuwa G. Hypertension management in older adults. Avicenna J Med 2018; 8:65-6.doi: 10.4103/ HEARTVIEWS. HEARTVIEWS_28_18. 